\title{
EFFECT OF STRENGTH AND ENDURANCE TRAINING PROGRAM ON MENTAL AND PHYSICAL HEALTH OF SPINAL CORD-INJURED PERSONS
}

\author{
Kęstutis Skučas \\ Lithuanian Sports University, Kaunas, Lithuania
}

\begin{abstract}
Background. The aim of the research was to examine the effects of eight weeks of strength and endurance training on the improvement of mental health and physical state of spinal cord-injured persons.

Methods. Twelve persons with spinal cord injury (SCI) participated in an eight-week intervention program of mainly two training types: strength and wheelchair driving endurance training. Subjects with SCI represented the experimental and control groups. The mental (Ware, 2000) and physical (isometric strength of the hand grip, strength of the shoulders and arms bench press, aerobic endurance $12 \mathrm{~min}$ and anaerobic endurance $30 \mathrm{~s}$ driving the wheelchair tests) values were evaluated before and after the program.

Results. After the primary questioning of the experimental group participants before organizing strength and endurance training program and the final questioning after the program, it was revealed that most values of mental health improved. The physical state characteristics of persons with spinal cord injury revealed differences between pre-test and post-test values.

Conclusions. This study indicated that persons with spinal cord injury involved in eight weeks strength and endurance training program improved mental and physical health parameters in comparison with persons with spinal cord injury not participating in any training program. Isometric force and $12 \mathrm{~min}$ wheelchair driving are good markers for strength, power and endurance in persons with spinal cord injury.
\end{abstract}

Keywords: strength and endurance training, psychical and physical health, spinal cord-injured persons.

\section{INTRODUCTION}

$\Lambda$ $s$ a result of a spinal cord injury, the somatic and autonomic nervous system is damaged. The most serious consequence is paralysis of muscles below the level of the lesion, depending in severity on the completeness and level of lesion. Secondary complications may occur as a consequence of spinal cord injury, such as urinary tract infections, spasticity, hypotension, autonomic dysreflexia, pressure sores, arm overuse injuries, fractures, venous thrombosis and respiratory infections (Giacobbi, Stancil, Hardin, \& Bryant, 2009). Moreover, having lost a considerable part of the functioning of their (lower) body, often leading to a wheelchair-dependent life, it is difficult for those with spinal cord injury to maintain an active lifestyle. As a consequence of the spinal cord injury, the secondary complications and the sedentary lifestyle of people with spinal cord injury, deconditioning is likely to occur with increased risk of obesity, diabetes and cardiovascular diseases (Martin, Jetha, Mack, \& Hetz, 2010; Valent, Dallmeijer, Houdijk, Talsma, E., \& van der Woude, 2007). Deconditioning in turn results in a lower physical capacity. Therefore people with such injuries will have difficulty in coping with the strain of daily activities (Hicks et al., 2011; Valent et al., 2007). They become less physically active, passive, have no motivation to achieve something, often leading to depression, bad mood, feeling helpless (Martin et al., 2010; Kennedy et al., 2010). 
Physically disabled persons often experience physical, emotional, psychological stress because they became dependent, passive, without trying to participate in everyday life actively (Columna, 2009; Tasiemski \& Brewer, 2011). People with spinal cord injury who are not able to participate in daily activities appear to be more handicapped (e.g. in the domains of physical independence and mobility) and tend to give lower ratings for quality of life (Tavakoli et al., 2016). To cope adequately with the strain of daily activities and to prevent longterm secondary health problems, it is important to have and maintain an optimum level of physical fitness. Physical fitness is often developed during initial rehabilitation and must be maintained in the process of a long-term physically active lifestyle and/or rehabilitation after care. This requires an understanding and the availability of evidencebased training methods and exercise protocols for people with spinal cord injury. Although guidelines for upper body training in people with spinal cord injury have been published by several authors, the experimental evidence base of these guidelines is unclear (Sisto \& Evans, 2014). That is why in scientific literature, new means and ways how to improve mental and physical health of spinal cord-injured persons are being searched (Hicks et al., 2011; Giacobbi et al., 2009). Most training programs for persons after spinal cord injuries are long-term and last from 12 to 16 weeks (Hicks et al., 2011; Lovell, Shields, Beck, Cuneo, \& McLellan, 2012). However, the impact of shorterterm moderate intensity combined strength and endurance training on wheelchair users remains unclear. The question about endurance progress of wheelchair users in a short period of time has to be answered. The information is useful for professionals working in the fields of rehabilitation, recreation and physical activity enhancement with persons after spinal cord injury because it shows the possibilities to achieve maximum results of mental and physical health in the indicators vital for this population. Such information can also be useful in planning training, allowing achieving best strength and cardio-respiratory system results, improvement of psychical health in a shorter period of time and further development of special skills important for a specific sport.

The aim of the research was to examine the effects of eight weeks of strength and endurance training for the improvement of mental health and physical state of spinal cord-injured persons.

\section{METHODS}

Subjects. Twelve spinal cord-injured persons with paraplegia after complete spinal cord injury in thoracic and lumbar lesion participated in the investigation. Subjects with SCI represented the experimental and control groups. The age of the subjects ranged from 19 to 32 years, the history of spinal cord injury was from 3 to 18 years. Their physical characteristics were $175(7.2) \mathrm{cm}$ height and 71.2 (4.6) $\mathrm{kg}$ weight. All the subjects had an acquired disability.

The experimental procedures were approved by the Kaunas Region Biomedical Research Ethics Committee.

The experiment. To address the primary hypothesis of this investigation that spinal cordinjured persons profit from strength and endurance training, all the subjects were assigned to the 8 -week resistance and endurance training regimen.

The following variables were assigned as dependent variables: isometric strength of the hand grip, strength of the shoulders and arms (bench press), $12 \mathrm{~min}$. aerobic endurance, and $30 \mathrm{~s}$ anaerobic endurance while driving the wheelchair were measured, and then mental health values were evaluated. Assessments were performed before and after the training period.

The participants of the control group did not participate in experimental program.

The participants of the experimental group had four training sessions per week, two hours per training session in the gym (two times per week strength training) and endurance training (two times per week).

Endurance training sessions were subject to moderate-intensity physical activity HR peak $60 \%$, the maximum pulse $167 \mathrm{bt} \cdot \mathrm{min}^{-1}$, and the average pulse $146 \mathrm{bt} \cdot \mathrm{min}^{-1}$. Wheelchair rides were performed 4 times for 30 minutes each with 5 minutes recovery phase.

Exercises for improving strength were applied with circuit training sessions in the gym using facilities and equipment adapted for wheelchair users spinal cord-injured persons. Each session was divided into the warm-up part, the main part and the cool-down part. During the warm-up, athletes with disability stretched their shoulder muscles for 10 min. During the main part of the session, the subjects completed 3 sets of $8-12$ repetitions of 8 different strength exercises designed for the shoulder muscles. Two hours strength training sessions were 
subject to moderate-intensity physical activity HR peak $65 \%$, the maximum pulse $172 \mathrm{bt} \cdot \mathrm{min}^{-1}$, and the average pulse $149 \mathrm{bt} \cdot \mathrm{min}^{-1}$.

For determining values of psychical health questions of evaluating psychical health statements from SF-36 questionnaire (Ware, 2000) were used. Vitality, energy, emotional state of spinal cordinjured persons were evaluated from 1 (the worst rate) to 6 (the best rate) points.

For evaluating isometric strength hand grip the subject was asked to squeeze the dynamometer ((Jamar, USA) with maximum isometric effort, which was maintained for about 5 seconds. Best of three attempts with $30 \mathrm{~s}$ rest between them was recorded.

For evaluating maximal strength of the shoulders and arms, each subject was asked to complete lifting the maximal weight (one repetition) lying in the bench trials (preliminary, after 8 weeks).

Evaluating aerobic endurance $12 \mathrm{~min}$ wheelchair driving, subjects lined up on the baseline (basketball court, length $28 \mathrm{~m}$ ) on a start sign started sprinting to far baseline and back. The total distances per 12 min to complete the test were recorded.

Evaluating anaerobic endurance $30 \mathrm{~s}$ wheelchair driving, subjects lined up on the baseline (basketball court, length $28 \mathrm{~m}$ ) and on a start sign started sprinting to far baseline and back. The total distances per $30 \mathrm{~s}$ to complete the test were recorded.

Statistical Analyses. The results were processed using SPSS. All the results are reported as mean and standard deviations. A paired $t$-test was used to compare pre- and post-test values for the control and experimental groups to determine statistical significance. The significance level was set at $p<.05$.

\section{RESULTS}

After the primary questioning of the experimental group participants before organizing strength and endurance training program and the final questioning after the program, it was revealed that most values of mental health improved (Table 1). Strength and endurance exercises stimulated positive emotions and increased energy, vitality, fullness of life, feelings of quietness, peacefulness and happiness of physically disabled persons. After the strength and endurance training program, physically disabled less experienced negative

\begin{tabular}{|l|c|c|}
\hline \multicolumn{1}{|c|}{$\begin{array}{c}\text { Mental and emotional well- } \\
\text { being }\end{array}$} & $\begin{array}{c}\text { Mean values of SCI persons } \\
\text { before the program (points) }\end{array}$ & $\begin{array}{c}\text { Mean values of SCI persons after } \\
\text { the program (points) }\end{array}$ \\
\hline Sensational fullness of life & $4.5 \pm 0.25$ & $5.7^{*} \pm 0.05$ \\
\hline Nervousness & $3.9 \pm 0.21$ & $5.3^{*} \pm 0.03$ \\
\hline Bad mood feeling & $4.3 \pm 0.68$ & $5.6^{*} \pm 0.12$ \\
\hline $\begin{array}{l}\text { Feeling of quietness and } \\
\text { peacefulness }\end{array}$ & $4.5 \pm 0.16$ & $5.9^{*} \pm 0.24$ \\
\hline Energy & $4.8 \pm 0.26$ & $6.0^{*} \pm 0.12$ \\
\hline Sadness and gloominess & $5.5 \pm 0.31$ & $5.7 \pm 0.06$ \\
\hline Depletion feeling & $4.9 \pm 0.19$ & $5.4 \pm 0.45$ \\
\hline Feeling of happiness & $4.7 \pm 0.02$ & $5.7^{*} \pm 0.13$ \\
\hline Tiredness & $4.5 \pm 0.3$ & $5.8^{*} \pm 0.15$ \\
\hline
\end{tabular}

Table 1. Values of mental health of experimental group of spinal cordinjured persons before and after the program

\begin{tabular}{|l|c|c|}
\hline \multicolumn{1}{|c|}{ Physical tests } & $\begin{array}{c}\text { Mean values of SCI persons } \\
\text { before the program }\end{array}$ & $\begin{array}{c}\text { Mean values of SCI persons } \\
\text { after the program }\end{array}$ \\
\hline $\begin{array}{l}\text { Isometric strength of the } \\
\text { hand grip (kg) }\end{array}$ & $50.4 \pm 0.24$ & $58.6^{*} \pm 0.23$ \\
\hline $\begin{array}{l}\text { Strength of the shoulders and } \\
\text { arms (bench press) (kg) }\end{array}$ & $69.2 \pm 2.12$ & $78.9^{*} \pm 3.34$ \\
\hline $\begin{array}{l}\text { Endurance 12 min wheel- } \\
\text { chair driving (m) }\end{array}$ & $10.3 \pm 2.02$ & $151.2^{*} \pm 3.87$ \\
\hline $\begin{array}{l}\text { Anaerobic endurance 30 s } \\
\text { wheelchair driving (m) }\end{array}$ & $68.9 \pm 0.22$ & $79.8^{*} \pm 0.16$ \\
\hline
\end{tabular}

Note. $*-$ statistically significant difference $(p<$ $.05)$ between values of mental health of participants before and after the program.

Table 2. Values of physical state in control group spinal cord-injured persons before and after the program

Note. ${ }^{*}$ - statistically significant difference $(p<.05)$ between values of physical state of participants in the experimental group before and after the program. 
feelings: less nervousness, they rarely had bad mood, sadness and gloominess, they were less stressed and tired. The values of mental health of the control group did not change after the experiment.

The physical state characteristics of persons with spinal cord injury revealed differences between pre-test and post-test values (Table 2).

The physical state values of the control group did not change after the experiment.

\section{DISCUSSION}

The major finding of the current study was that eight weeks of strength and endurance training significantly improved mental and physical health of spinal cord-injured persons. The data of the study suggest that improvement of mental health and physical state is closely dependent on the type of training and on the period of training. Eight-week moderate intensity strength and endurance training exercises have more potential to improve mental and physical health parameters in comparison with a longer term (12 and 16 weeks) training as it was documented in the current study. This type of training seems to have an advantage in constructing training plans for persons with spinal cord injury to gain a high level of strength and endurance basis, and then it could be continued with a high intensity exercise training period specified by sport competition conditions.

Because of disability and restrictions of movement in non-accessible environment, physically disabled persons often experience disorders of psychical health. They become nervous, tense, experiencing feelings of frustration with life and the current situation. According to the data of the study, strength and endurance exercises have a positive effect on values of psychical health in spinal cord-injured persons. After strength and endurance training, participants felt energy, vitality, experienced fullness of life, feelings of quietness, peacefulness and happiness. The data of the study reveal the fact that exercises performed in the gym and in the stadium had a positive effect on mood in physically disabled persons helping to relax their nervous system, preventing depression and negative feelings, senses of depletion and tiredness that often accompanied severe disabilities (Kennedy et al., 2010).

Strength and endurance training is important for persons with spinal cord injury, as it was documented in this study. These findings are important because some authors and coaches speculated about minor adaptation capacities to training exercises in subjects with spinal cord injury in general. Evaluation of aerobic performance can be used to analyse the functioning of cardiovascular, respiratory and neuromuscular systems, providing a global assessment of the integrative physiological responses and probable relationship with functional capability (De Groot et al., 2012). Nevertheless, it is difficult to compare the results of different studies that have measured aerobic performance because they differ in a number of factors, including type of tests (MSFT, Cooper, Leger), or the variables measured $\left(\mathrm{VO}_{2} \mathrm{max}\right.$, distance, $\mathrm{HR}$, lactate). In this study, persons with spinal cord injury showed a significant $(p<.01)$ difference between pre- and post-test a mean distance covered of $1512 * \pm 387 \mathrm{~m}$. In any case, the mean distance covered values in our subjects are lower than those reported in the literature for international wheelchair basketball players (De Groot et al., 2012; Yanci et al., 2015).

Isometric strength (IS) value was improved in the post training period by $16 \%$. Previous studies showed a big range in strength values between pre- and post-test, ranging from $12 \%$ to $30 \%$ (Valent et al., 2007). The current study showed similar results of strength values in comparison with the mean value given in literature (Valent et al., 2007). It documents, the eight week moderateintensity strength and endurance training had an impact on IS value for spinal cord injured persons. The improvement of IS could be considered to be small in comparison with studies of some authors (de Groot et al., 2003). De Groot et al. (2003) demonstrated a $46 \%$ of improvement after 16 weeks of intensive endurance and strength training. However, it is difficult to compare these data because of the different content of the program applied in this study and very low initial data of the participants. It seems that the moderate-intensity strength and endurance eight-week training positively influenced the improvement of strength of the upper body, the trunk stability and muscular coordination in spinal-cord injured persons.

\section{CONCLUSIONS}

In conclusion, this study indicated that persons with spinal cord injury involved in eight weeks strength and endurance training program improved mental and physical health parameters in comparison with persons with spinal cord injury not participating in any training program. Isometric force and $12 \mathrm{~min}$ wheelchair driving are good markers for strength, power and endurance in persons with spinal cord injury. 


\section{REFERENCES}

Columna, L. (2009). Principles and methods of adapted physical education and recreation. Adapted Physical Activity Quarterly, 27, 72-75.

De Groot, P. C. E., Hjeltnes, N., Heijboer, A. C., Stal, W., \& Birkeland, K. (2003). Effect of training intensity on physical capacity, lipid profile and insulin sensitivity in early rehabilitation of spinal cord injured individuals. Spinal cord, 41(12), 673. https://doi. org/10.1038/sj.sc.3101534

De Groot, S., Balvers, I. J., Kouwenhoven, S. M., \& Janssen, T. W. (2012). Validity and reliability of tests determining performance-related components of wheelchair basketball. Journal of Sports Sciences, 30(9), 879-887. https://doi.org/10.1080/02640414.201 2.675082

Giacobbi, P. R., Stancil, M. Jr., Hardin, B., \& Bryant, L. (2009). Physical activity and quality of life experienced by highly active individuals with physical disabilities. Adapted Physical Activity Quarterly, 26(3), 189-207.

Hicks, A. L., Martin Ginis, K. A., Pelletier, C. A., Ditor, D. S., Foulon, B., \& Wolfe, D. L. (2011). The effects of exercise training on physical capacity, strength, body composition and functional performance among adults with spinal cord injury: A systematic review. Spinal Cord, 48, 65-72. https://doi.org/10.1038/ sc. 2011.62

Kennedy, P., Smithson, E., McClelland, M., Short, D., Royle, J., \& Wilson, C. (2010). Life satisfaction, appraisals and functional outcomes in spinal cordinjured people living in the community life satisfaction, appraisals and functional outcomes. Spinal Cord, 48, 144-148. https://doi.org/10.1038/sc.2009.90
Lovell, D., Shields, D., Beck, B., Cuneo, R., \& McLellan, C. (2012). The aerobic performance of trained and untrained handcyclists with spinal cord injury. European Journal of Applied Physiology, 112(9), 3431-3437. https://doi.org/10.1007/s00421-012-2324-X Martin, K. A., Jetha, A., Mack, D. E., \& Hetz, S. (2010). Physical activity and subjective well- being among people with spinal cord injury: A meta-analysis physical activity and subjective well-being. Spinal Cord, 48, 65-72.

Sisto, S.A., \& Evans, N. (2014). Activity and fitness in spinal cord injury: Review and update. Current Physical Medicine and Rehabilitation Reports, 2, 147-157.

Tasiemski, T., \& Brewer, B. W. (2011). Athletic identity, sport participation, and psychological adjustment in people with spinal cord injury. Adapted Physical Activity Quarterly, 28(3), 233-250.

Tavakoli, S. A. H., Kavian, M., Bakhsh, S. C., Ghajarzadeh, M., Hamedan, M. S., Ghazwin, M. Y., \& Latifi, S. (2016). Is level of injury a determinant of quality of life among individuals with spinal cord injury? A tertiary rehabilitation center report. Oman Medical Journal, 31(2), 112.

Valent, L., Dallmeijer, A., Houdijk, H., Talsma, E., \& van der Woude, L. (2007). The effects of upper body exercise on the physical capacity of people with a spinal cord injury: A systematic review. Clinical Rehabilitation, 21(4), 315-330. doi: 10.1177/0269215507073385

Yanci, J., Granados, C., Otero, M., Badiola, A., Olasagasti, J., \& Bidaurrazaga-Letona, I. (2015). Sprint, agility, strength and endurance capacity in wheelchair basketball players. Biology of Sport, 32, 71-8. doi: $10.5604 / 20831862.1127285$ 